\title{
Early diagnosis of left ventricular diastolic dysfunction in diabetic patients: a possible role for natriuretic peptides
}

\author{
Silvio Romano ${ }^{1 *}$, Michele Di Mauro' ${ }^{1}$ Simona Fratini ${ }^{1}$, Leonello Guarracini ${ }^{2}$, Fabrizio Guarracini ${ }^{1}$, Gianfranco Poccia ${ }^{3}$,
} Maria Penco ${ }^{1}$

\begin{abstract}
Background: The aim of the present study was to verify whether BNP might detect pre-clinical diastolic dysfunction (LVDD) in type-2 diabetic patients.

Methods: One-hundred and twenty-seven consecutive outpatients with type-2 diabetes mellitus were enrolled into the study. Subjects with overt heart failure or NYHA class $>1$, history of coronary artery disease, severe valvulopathy or chronic atrial fibrillation were excluded from the study. All patients underwent clinical evaluation, laboratory assessment of brain natriuretic peptide (BNP) and echocardiographic examination.

Results: No patients showed systolic impairment of left ventricular function, whereas diastolic dysfunction was detected in 53 (42\%) cases (all impaired relaxation). Median BNP was 27 pg/ml without any significant difference between 76 patients with normal left ventricular function and 53 with diastolic dysfunction; in 54 (43\%) patients showing HBA1C $\geq 8$ (uncontrolled diabetes) normal function was found in 32 and diastolic dysfunction in 22, with a significant difference of BNP at multivariate analysis $(\mathrm{OR}=1.02,95 \% \mathrm{Cl}=1.05-1.09, \mathrm{p}=0.003)$. In uncontrolled diabetic cohort, BNP was a strong predictor for $\operatorname{LVDD}(\mathrm{OR}=2.7,95 \% \mathrm{Cl}=1.3-5.6, \mathrm{p}=0.006)$ along with the duration of diabetes $(\mathrm{OR}=1.6,95 \% \mathrm{Cl}=1.1-2.9, \mathrm{p}=0.046)$. BNP $>25 \mathrm{pg} / \mathrm{ml}$ was a cut-off value with high accuracy to detect a LVDD.

Discussion: Early screening of high-risk patients for diabetic cardiomyopathy development might be useful to better control glycemic profile in order to reduce heart disease progression or even to reverse it

Conclusions: BNP could be a cheap, easy and useful tool to screen those ones with preclinical ventricular diastolic dysfunction in a subset of patients particularly prone to develop cardiovascular complications, like uncontrolled diabetic patients.
\end{abstract}

\section{Background}

Diabetes mellitus (DM) is not only a significant independent risk factor for developing of atherosclerotic ischemic heart disease or ventricular hypertrophy but it is also able to trigger a diabetic cardiomyopathy due to some dysmetabolic processes: inhibition of switching within the cardiomyocite from free-fatty acid (FFA) to glucose metabolism, dysregulation of FFA metabolism with increased uptake, reduced FFA oxidation, reduction

\footnotetext{
*Correspondence: silvio.romano@cc.univaq.it

${ }^{1}$ Cardiology, Department of Internal Medicine and Public Health, University of L'Aquila, Italy

Full list of author information is available at the end of the article
}

of peroxisome proliferator-activated receptors (PPAR), increase of PPAR- $\gamma$ and insulin-resistance, increased intracellular lipogenesis which leads to cardiomyocite lipotoxiocity [1].

The patients with type-2 DM are at 2-5 folds higher risk for developing heart failure (HF) [2]. Some large trials reported that the prevalence of diabetes in patients with chronic heart failure is around $30 \%$ and close to $50 \%$ in those with acute HF [3-5] The first stage of diabetic cardiomyopathy is represented by left ventricular diastolic dysfunction (LVDD) with preserved systolic function, in an asymptomatic pattern [6-9]; the prevalence of diastolic dysfunction largely ranges from $30 \%$ to

\section{C) Biomed Central}


$75 \%$, depending on the echocardiographic parameters used to define it $[7,10-13]$.

Internationally, there is an increased focus on prevention since even pre-clinical diabetic cardiomyopathy can impair significantly event-free survival [14], thus, in order to deal with this issue, neurohormonal profile of diabetic patients could be a good tool to screen subclinical ventricular dysfunction instead of cardiac imaging technique, which required elevated costs and human resource expenditure. For this purpose, brain natriuretic peptide (BNP) was demonstrated to be a good diagnostic and prognostic marker in diabetic patients with heart failure [15], systolic dysfunction [16], silent myocardial ischemia [17] and vascular complications [18]. The diagnostic role of natriuretic peptides for detecting LVDD in asymptomatic diabetic patients is still debated [14,17,19-21].

Hence, the aim of the present study is to verify whether BNP might detect pre-clinical diastolic dysfunction in type- 2 diabetic patients.

\section{Methods}

\section{Study population}

One hundred and twenty-seven consecutive outpatients (age range 35-65 years, mean \pm SD $55 \pm 7$ years), with type- 2 diabetes mellitus according to ADA/WHO criteria [22] were enrolled into the study. Subjects with overt heart failure or NYHA class $>1$, history of coronary artery disease, severe valvulopathy or chronic atrial fibrillation were excluded from the study.

All patients underwent clinical evaluation, laboratory assessment of BNP and echocardiographic examination (Table 1). Concerning antidiabetes therapy, $9 \%$ of them were on insulin treatment, $60 \%$ took oral antidiabetes agents and 6\% had both treatments; the remaining 31\% of patients were on diet. Other therapies were ACEinhibitors (22\%), ARB (9\%), $\beta$-blockers (10\%), calciumchannel blockers (6\%), $\alpha$-blockers (4\%) and diuretics (12\%).

All patients gave their written informed consent; the investigation conforms to the principles outlined in the Declaration of Helsinki and the study was approved by the local ethics committee (The University of L'Aquila).

\section{Laboratory}

Blood samples were taken after 5 minutes of supine rest. BNP was measured using the commercially available AxSYM BNP assay, produced by Axis-Shield and Abbott Laboratories. Glycated hemoglobin (HBA1C) were measured using Menarini HA8140 assay. Microlabuminuria was defined as extemporary albuminuria value equal or greater than $20 \mathrm{mg} / \mathrm{L}$.

\section{Echocardiography}

M-mode, two-dimensional images and pulsed-wave and color-flow-Doppler examinations were performed on the same day of BNP assays, with a commercially available imaging system (ESAOTE MyLAB 30). Left ventricular systolic and diastolic volumes and ejection fraction (EF) were derived from the biplane apical modified Simpson's rule algorithm. Left ventricular dimensions were measured from M-mode images according to standard criteria. Diastolic dysfunction was assessed by means of transmitral pulsed-wave Doppler velocity (E/A ratio), deceleration time. In addition, pulmonary venous systolic and diastolic flow velocities were obtained as the

Table 1 Demographic, clinical and echocardiographic characteristics

\begin{tabular}{|c|c|c|c|c|}
\hline POPULATION & $\begin{array}{c}\text { OVERALL } \\
\mathrm{n}=127\end{array}$ & $\begin{array}{c}\text { Group A } \\
\mathrm{N}=74\end{array}$ & $\begin{array}{c}\text { Group B } \\
\mathrm{N}=53\end{array}$ & $\mathrm{p}$-value \\
\hline Age (years) & $55.2 \pm 6.8$ & $54.5 \pm 6.8$ & $56.3 \pm 6.8$ & 0.155 \\
\hline Gender (M/F) & $65 / 62$ & $38 / 36$ & $24 / 29$ & 0.500 \\
\hline BMI (Kg/m2) & $29.2 \pm 5.0$ & $29.1 \pm 5.1$ & $29.5 \pm 5.2$ & 0.867 \\
\hline Diabetes duration (years)* & $3(1-10)^{*}$ & $3(1-10)^{*}$ & $3(1-9)$ & 0.954 \\
\hline Smokers & $28(22 \%)$ & $14(19 \%)$ & $14(26 \%)$ & 0.577 \\
\hline Ex-smokers & $40(31 \%)$ & $25(34 \%)$ & $15(28 \%)$ & 0.504 \\
\hline Hypertension & $51(40 \%)$ & $27(37 \%)$ & $24(45 \%)$ & 0.361 \\
\hline Hypercholesterolemia & $29(23 \%)$ & $19(26 \%)$ & $10(19 \%)$ & 0.447 \\
\hline Creatinine (mg/dl) & $0.89 \pm 0.21$ & $0.87 \pm 0.21$ & $0.94 \pm 0.21$ & 0.115 \\
\hline Microalbuminuria & $34(29 \%)$ & $18(28 \%)$ & $16(31 \%)$ & 0.666 \\
\hline LVEF (\%) & $59.4 \pm 4.8$ & $60.5 \pm 5.5$ & $58.8 \pm 3.7$ & 0.143 \\
\hline LVMI (g/m2.7) & $43.7 \pm 11.8$ & $42.6 \pm 12.1$ & $45.2 \pm 11.3$ & 0.198 \\
\hline $\mathrm{LVH}$ & $51(40 \%)$ & $27(36 \%)$ & $24(45 \%)$ & 0.361 \\
\hline
\end{tabular}

LVEF = left ventricular ejection fraction, LVMI = left ventricular mass index, LVH = left ventricular hypertrophy.

*data are expressed as median and interquartile range. 
maximal value reached during the corresponding phase of each cardiac cycle. Diastolic dysfunction was classified into 3 categories as follows: impaired relaxation, pseudonormal filling pattern and restrictive-like filling pattern, as previous reported [23]. Left ventricular mass (LVM) was calculated according to the following formula: $0.8 \times[1.04$ $\left.(\mathrm{IVS}+\mathrm{LVDD}+\mathrm{PWT})^{3}-\mathrm{LVDD}^{3}\right]+0.6 \mathrm{~g}$ [24]. All echocardiographic data were indexed by height to the allometric power of 2.7 [25] Left ventricular hypertrophy was defined as an LVM $\geq 50 \mathrm{~g} / \mathrm{m}^{2.7}$ in men and $\geq 47 \mathrm{~g} / \mathrm{m}^{2.7}$ in women.

A single observer (LG) made all measurements. Using digital archiving images, intraobserver variability was tested in a blinded fashion. Intraobserver variability was $3.3 \%, 3.9 \%, 5.1 \%, 8.5 \%$ and $9.2 \%$ for $\mathrm{E} / \mathrm{A}$ ratio, $\mathrm{E}$ wave deceleration time, pulmonary venous systolic and diastolic flow velocities, EF and calculated left ventricular mass index (LVMI), respectively.

\section{End-points}

The aim of this study was to evaluate the diagnostic role of BNP assays in early identification of diastolic dysfunction in diabetic patients, asymptomatic for heart failure. Particularly, since that an uncontrolled diabetes is strongly related to development of left ventricular dysfunction and chronic heart failure [21], a further analysis has been performed in this particular subset of patients. To define uncontrolled diabetes, an average of last two years HBA1C values were used; HBA1C equal or higher of $8 \%$ was chosen as threshold for uncontrolled diabetes, more prone to develop heart and vascular complications [26].

\section{Statistics}

Results were expressed as mean ( \pm standard deviation) for normally distributed continuous variables, whereas non-normally distributed data were expressed as median and interquartile range (IQR): $25^{\text {th }}$ and $75^{\text {th }}$ percentile; Categorical variables were reported as count and percentage. Distribution of continuous variables was tested for normal distribution using the Kolmogorov-Smirnov test. Paired-comparison was performed by means of Wilcoxon test whereas unpaired-comparison was performed by means of t-test or Mann-Whitney U test. Categorical data were compared by X2-test or Fisher exact test where appropriate. Logistic regression was used to identify predictive factors for LVDD. The variables initially inserted into the regression model were: age, gender, body mass index, systolic blood pressure, diastolic blood pressure, diabetes duration (years) smokers/ex-smokers, hypertension, hypercholesterolemia, obesity (BMI $>30 \mathrm{Kg} / \mathrm{m} 2)$, left ventricular mass index (g/m2.7), last 2-year average HBA1C (\%), creatinine $(\mathrm{mg} / \mathrm{dl})$, microalbuminuria, type of antidiabetic therapy, type of anti-hypertensive medication, BNP, hypertension plus left ventricular hypertrophy (duration of diabetes and BNP were non-normally distributed and so they underwent log-transformation before being inserted into the initially model). Variables included in the final model were reported as odd ratio (OR), 95\% confidence interval $(\mathrm{CI})$ and $\mathrm{p}$-value.

Receiver operating characteristic (ROC) curve analysis was used to identify predictive cut-offs. Each statistical analysis was validated in 1000 bootstrap samples. A probability value $\mathrm{p}<0.05$ was considered significant. The retrospective power calculation, using as target end-point the comparison of BNP levels between uncontrolled diabetic patients with versus without diastolic dysfunction, estimates that 18 cases were the minimum sample size per each group to achieve a power of $80 \%$ with an $\alpha$-error of 0.05 .

All analyses were performed with the statistical software package SPSS (SPSS Inc, Chicago, IL, US).

\section{Results}

No patients showed systolic impairment of left ventricular function, whereas diastolic dysfunction was detected in 53 (42\%) cases; all of them were classified as impaired relaxation pattern; all the remaining 74 cases showed normal diastolic function. All the population had a creatinine equal or below $1.5 \mathrm{mg} / \mathrm{dl}$; microalbuminuria was present in $29 \%$ of cases without any difference between patients with and without ILDD (Table 1)

Overall BNP median value was $27 \mathrm{pg} / \mathrm{ml}(\mathrm{IQR}=6-55)$ without any significant difference between 76 patients with normal left ventricular function (Group A) and those ones with diastolic dysfunction (Group B) (Figure 1). The

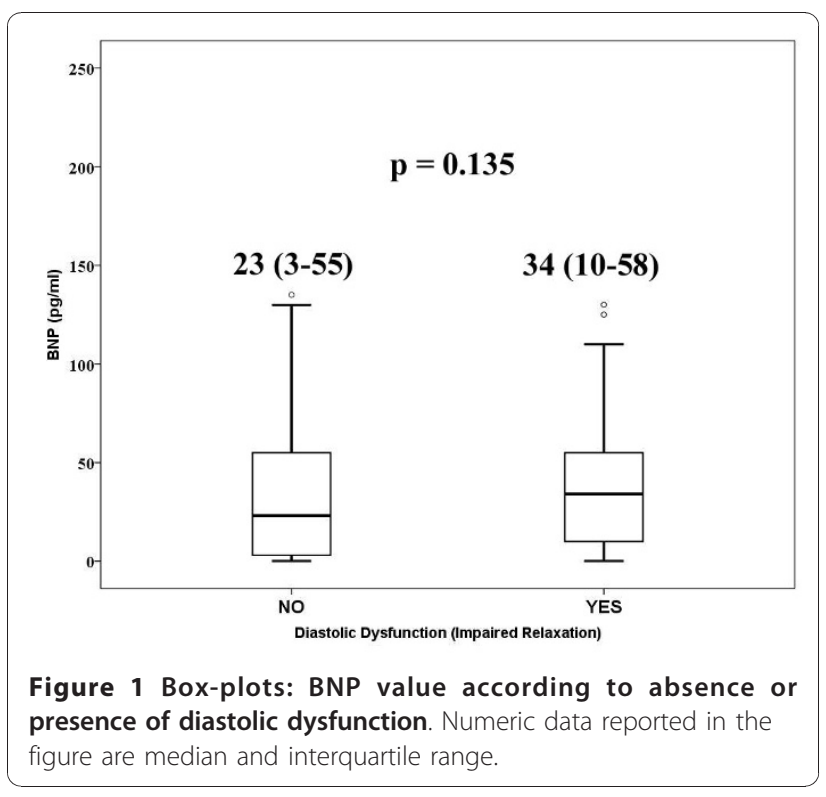


Table 2 Difference between patient without and with diastolic dysfunction, in uncontrolled diabetic cohort (HBA1C $\geq 8 \%$ )

\begin{tabular}{|c|c|c|c|}
\hline POPULATION & $\begin{array}{c}\text { Group A } \\
n=32\end{array}$ & $\begin{array}{c}\text { Group B } \\
n=22\end{array}$ & p-value \\
\hline Age (years) & $52.6 \pm 6.8$ & $54.5 \pm 8.4$ & 0.355 \\
\hline Gender (M/F) & $17 / 15$ & $9 / 13$ & 0.377 \\
\hline $\mathrm{BMI}(\mathrm{Kg} / \mathrm{m} 2)$ & $29.5 \pm 5.1$ & $30.2 \pm 5.7$ & 0.691 \\
\hline Diabetes duration (years)* & $4(0.7-10)$ & $7(3-10)$ & 0.225 \\
\hline Smokers & $6(19 \%)$ & $8(36 \%)$ & 0.303 \\
\hline Ex-smokers & $8(25 \%)$ & $5(23 \%)$ & 0.848 \\
\hline Hypertension & $7(22 \%)$ & $8(36 \%)$ & 0.243 \\
\hline Hypercholesterolemia & $8(25 \%)$ & $5(23 \%)$ & 0.848 \\
\hline Creatinine $(\mathrm{mg} / \mathrm{dl})$ & $0.90 \pm 0.22$ & $0.95 \pm 0.24$ & 0.407 \\
\hline Microalbuminuria & $33(33 \%)$ & $30(30 \%)$ & 1.000 \\
\hline LVEF (\%) & $58.8 \pm 5.2$ & $58.9 \pm 3.4$ & 0.922 \\
\hline LVMI $(\mathrm{g} / \mathrm{m} 2.7)$ & $38.7 \pm 9.8$ & $40.9 \pm 11.4$ & 0.461 \\
\hline $\mathrm{LVH}$ & $4(13 \%)$ & $6(27 \%)$ & 0.170 \\
\hline $\mathrm{HBA} 1 \mathrm{C}$ & $9.3 \pm 1.6$ & $9.4 \pm 1.8$ & 0.707 \\
\hline Insulin & $7(22 \%)$ & $4(18 \%)$ & 0.741 \\
\hline Oral antidiabetic agents & $18(56 \%)$ & $15(68 \%)$ & 0.377 \\
\hline
\end{tabular}

$\mathrm{LVEF}=$ left ventricular ejection fraction, $\mathrm{LVMI}=$ left ventricular mass index, $\mathrm{LVH}=$ left ventricular hypertrophy.

*data are expressed as median and interquartile range.

only variable included into the final logistic regression model was the contemporary presence of hypertension and left ventricular hypertrophy $(\mathrm{OR}=2.6,95 \% \mathrm{CI}=1.1$ $6.5, \mathrm{p}=0.044)$.

Last two-year average $\mathrm{HBA} 1 \mathrm{C}$ value was $7.7 \pm 1.8$ without any difference between the two groups (diastolic dysfunction $7.7 \pm 1.8$ vs normal function $7.7 \pm 1.9$, p = 0.905); Fifty-four (43\%) out of 127 patients showed HBA1C $\geq 8$ (uncontrolled diabetes) with a mean value of $9.3 \pm 1.7$. The remaining group of patients (73) showed a mean HBA1C of $6.5 \pm 0.6$ (p vs uncontrolled diabetes $<0.001$ ). In 73 patients with well-controlled diabetes, BNP level was not predictive for diastolic dysfunction $(\mathrm{p}=0.244)$, whereas BNP seems to be a good predictive in the uncontrolled-diabetes cohort

The uncontrolled diabetes group was split into 2 groups: normal function (Group A, $\mathrm{n}=32$ ) and diastolic dysfunction (Group B, $\mathrm{n}=22$ ). The two groups did not show any difference concerning demographic, clinical, echocardiographic data (table 2).

The value of BNP was significantly higher in group B than in group A (Figure 2); the binary logistic regression confirmed that BNP was related to higher prevalence of LVDD (Log-transformation: OR $=2.7,95 \% \mathrm{CI}=1.3-5.6$, $\mathrm{p}=0.006$ ) along with the duration of diabetes (Logtransformation: $\mathrm{OR}=1.6,95 \% \mathrm{CI}=1.1-2.9, \mathrm{p}=0.046)$. Moreover, BNP was a strong predictor for LVDD in

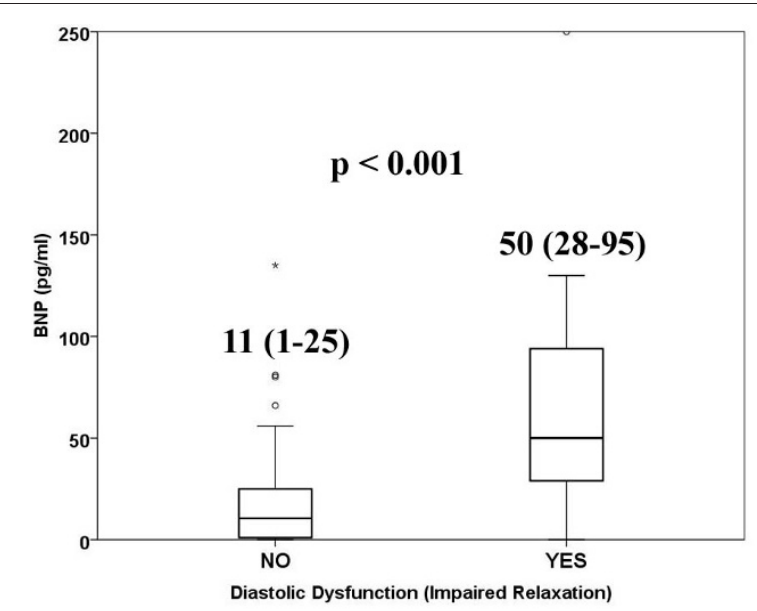

Figure 2 Box-plots: BNP value according to absence or presence of diastolic dysfunction, in uncontrolled diabetic cohort. Numeric data reported in the figure are median and interquartile range.

uncontrolled diabetes cohort $(\mathrm{AUC}=0.80,95 \% \mathrm{CI}$ 0.66$0.89, \mathrm{p}<0.001$ ) with a cut-off value of $25 \mathrm{pg} / \mathrm{ml}$ above that the likelihood to show a DD is high (sensitivity = $77 \%$ and specificity $=78 \%$ ) (Figure 3 ); the rate of patients having BNP $>25 \mathrm{pg} / \mathrm{ml}$ was significantly higher in group B $(77 \%$ vs $22 \%, p<0.001)$.

\section{Discussion}

Prevalence of subclinical isolated diastolic dysfunction in type-2 diabetic population

Our data show a prevalence of asymptomatic diastolic dysfunction of roughly $42 \%$, perfectly included within the range, from $30 \%$ to $63 \%$, reported by those studies where LVDD was assessed by means of conventional echocardiography $[7,10-13,27,28]$. In our series, the presence of LVDD was independent by age and gender unlike reported by other Authors which clearly found a relationship between these factors and the prevalence of LVDD in diabetic patients $[7,10,11]$. Anyway, the presence of hypertension along with left ventricular hypertrophy increased the prevalence of LVDD up to $61 \%$ $(14 / 23)$ versus $38 \%(39 / 104), \mathrm{p}=0.040$; this result was confirmed also by binary logistic regression $(\mathrm{OR}=2.6$, $95 \% \mathrm{CI}=1.1-6.5, \mathrm{p}=0.044)$, corroborating that combination of DM and HTN has more severe impact on ventricular filling pattern [27].

However, the diastolic function was impaired also in $38 \%$ of 104 diabetic patients without $\mathrm{HTN}+\mathrm{LVH}$, similar either in presence of HTN or not $(\mathrm{p}=0.819)$. To explain the patho-physiological basis of this left ventricular impaired relaxation, the concept that diabetes per se might cause a stand-alone cardiomyopathy should be accepted [1]. Diabetic cardiomyopathy has been defined 


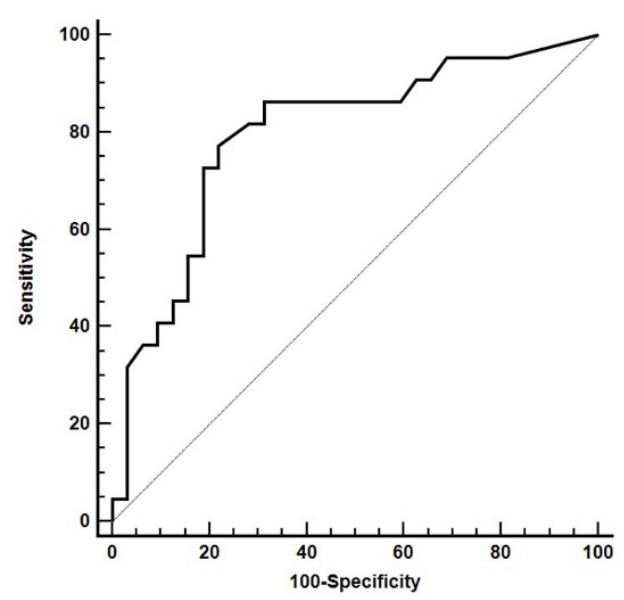

Figure 3 ROC curve: BNP is a good predictor for DD in out of control cohort.

as the presence of myocardial abnormalities in the absence of coronary artery disease, hypertension or other significant etiology [29] In a very recent report, Anderson and coworkers [30] compared two cohorts of 31 patients having EF > 35\%, without significant coronary artery disease (CAD), prior myocardial infarction, cardiac pacemaker, atrial fibrillation, or significant valve disease, one diabetic and the other one controls, matching the two groups on age, gender and presence of hypertension. The Authors concluded that In this set of patients diabetes is anyway associated with global diastolic dysfunction. This finding is in accordance with the hypotheses of increased myocardial stiffness, increased resting myocyte tension and deposition of advanced glycated end products associated with diabetic cardiomyopathy; In fact, intracellular hyperglycemia is at basis of formation of advanced-glycated end products (AGEs) as collagen, elastin and other connective tissue proteins [31] which produce myocardial fibrosis resulting in diastolic dysfunction.

\section{BNP and diastolic dysfunction}

The diagnostic role played by BNP in early detection of asymptomatic diastolic dysfunction in type- 2 diabetes is still controversial [14,16,19-21,32-34]. In our, series, we failed to identify any difference between patients with normal function and those ones with LVDD regarding BNP value (Figure 1). The possible explanation of this results can be the presence of just impaired relaxation in our population which represents the mild grade of LVDD [19,20]. In fact, Magnusson et al, [19] described a detecting role of BNP with respect to LVDD, but only in case of moderate-to-severe LVDD; comparing patients with and without mild LVDD the Authors did not find any difference $(\operatorname{lnBNP} 1.3 \pm 0.8$ vs $0.98 \pm 0.85, \mathrm{p}=0.09)$ and this finding was confirmed also at multivariate analysis. Conversely, comparing patients with moderate-tosevere LVDD, lnBNP was significantly higher $(2.1 \pm 1.4$ vs $\left.0.98 \pm 0.85,{ }^{\prime}<0.0001\right)$. Kiencke and co-workers [14] analyzed 100 adults with diabetes in order to evaluate if BNP could predict pre-clinical diastolic dysfunction in diabetic cardiomyopathy. They concluded that BNP had higher prognostic than diagnostic role. Although the ROC curve analysis identified BNP as predictor for diastolic dysfunction, the area under curve (0.70) showed a low accuracy of BNP test and the identified cut-off value of $34 \mathrm{pg} / \mathrm{dl}$ showed a moderate sensitivity (66\%) and specificity (71\%). The suggestion that BNP is very likely unable for early detection of LVDD was confirmed by others [20].

On the contrary, Albertini and co-workers [16] assessed BNP value in 91 consecutive patients with type 2 diabetes mellitus, finding that BNP level was significantly higher in patients with LVDD, especially in case of untreated hypertension ( $87 \pm 20$ vs $13 \pm 2$, p $<0.0001)$; anyway, comparing the mean value of patient with normal $\mathrm{LV}$ function with those ones with LVDD, independently from the anti-hypertensive treatment, BNP was significantly higher in the latter group $(\mathrm{p}<0.001)$. In another report, the area under the receiver-operating characteristic curve for NT-proBNP to separate normal versus diastolic dysfunction, in type 2 diabetic patients, was even 0.96 [32]. Kim et al [33] assessed NT-proBNP levels in a group consisted of 130 diabetic patients referred for echocardiography, finding that in diastolic dysfunction were significantly higher than normal group $(1491.1 \mathrm{pg} /$ $\mathrm{mL}$ versus $232.3 \mathrm{pg} / \mathrm{mL}, \mathrm{P}=0.01)$, even though there was no difference in ejection fraction (EF) $(61.2+/-7.9 \%$ versus $60+/-8.4 \%, P=0.773$ ).

\section{BNP and diastolic dysfunction in uncontrolled diabetic subset}

Also Dencker et al [21] demonstrated that BNP was significantly higher in patients with abnormal diastolic dysfunction $(26.0 \pm 3.4$ vs $5.3 \pm 3.4, \mathrm{p}<0.001)$ but in a cohort of 33 patients with poorly regulated type 2 diabetes. The authors defined "poorly regulated" when HBA1C > 7\%. In 2001, Menzin J et al [26] found that HBA $1 C<8 \%$ had roughly $60 \%$ fewer hospital admissions for complications, especially heart complications. Thus, we decided to perform a sub-analysis in 54 patients with uncontrolled diabetes (HBA1C $\geq 8 \%$ ), in order to verify if BNP might be a good tool for early detection of LVDD at least in this subset of patients. Both univariate and multivariate analysis confirmed that higher levels of BNP were associated with LVDD and ROC curve analysis demonstrated the good accuracy of this parameter for detecting LVDD; furthermore, a cut-off value was also identified $\mathrm{BNP}>25 \mathrm{pg} / \mathrm{ml}$, with a good sensitivity 
(77\%) and specificity (78\%) (Figure 3). This finding is consistent with the one reported by Albertini et al [16]. Conversely, in 73 patients with well-controlled diabetes, BNP level was not predictive for diastolic dysfunction.

\section{Limitations of the study}

The main limitation of this study is the small sample size. Another important limits is related to the echocardiographic assessment of diastolic dysfunction, that, nowadays, is more and more evaluated by means of tissue Doppler imaging (TDI).

\section{Clinical implications and Conclusion}

There is an important concept raising up from the present study, BNP is a good marker for detecting preclinical LVDD in a subset of patients particularly prone to develop cardiovascular complications, like those ones with uncontrolled diabetes. In clinical practice it is very difficult to submit all asymptomatic diabetic subjects to echocardiographic lab; so BNP could be a cheap, easy and useful tool to screen those ones with preclinical ventricular diastolic dysfunction among patients with high HBA1C. Furthermore, BNP could be use for serial assessment of this specific cohort of patients asymptomatic for heart failure.

Another clinical implication concerns the possibility to better control glycemic profile in order to reduce heart disease progression or even to reverse it, especially in patients with short duration of diabetes without history of cardiovascular event [35,36]; In fact, in the early stages of diabetes, structural modifications seem to be partially reversible [8]. Finally, early screening of those patients with subclinical diastolic dysfunction, is useful to plan a cardiologic therapy to prevent the development of diabetic cardiomyopathy.

\section{Author details \\ ${ }^{1}$ Cardiology, Department of Internal Medicine and Public Health, University of L'Aquila, Italy. ${ }^{2}$ Cardiac Rehabilitation, "Umberto I" Hospital, Tagliacozzo, Italy. Diabetology, "San Salvatore" Hospital, L'Aquila, Italy.}

\section{Authors' contributions}

MP and LG conceived and designed the study protocol, moreover gave their final approval of the manuscript. LG performed echocardiography. SF, FG, GP provided collection of data. SR and MDM performed analyses and prepared the manuscript. All authors have read and approved the manuscript.

\section{Competing interests}

The authors declare that they have no competing interests.

Received: 19 October 2010 Accepted: 16 December 2010 Published: 16 December 2010

\section{References}

1. Saunders J, Mathewkutty S, Drazner MH, McGuire DK: Cardiomyopathy in type 2 diabetes: update on pathophysiological mechanisms. Herz 2008, 33:184-90, Review.
2. Nichols GA, Gullion CM, Koro CE, et al: The incidence of congestive heart failure in type 2 diabetes: an update. Diabetes Care 2004, 27:1879-84.

3. Dries DL, Sweitzer NK, Drazner MH, Stevenson LW, Gersh BJ: Prognostic impact of diabetes mellitus in patients with heart failure according to the etiology of left ventricular systolic dysfunction. J Am Coll Cardiol 2001, 38:421-8

4. Jaarsma T, Van der Wal MH, Lesman-Leegte I, for the COACH Study Group, et al: Effect of moderate or intensive disease management program on outcome in patients with heart failure. The Coordinating study evaluating Outcomes of Advising and Counseling in Heart failure (COACH). Arch Intern Med 2008, 168:316-24

5. McMurray JJ, Teerlink JR, Cotter G, for the VERITAS Investigators, et al: Effects of tezosentan on symptoms and clinical outcomes in patients with acute heart failure. The VERITAS randomized controlled trials. JAMA 2007, 298:2009-19.

6. Galderisi M, Anderson KM, Wilson PW, Levy D: Echocardiographic evidence for the existence of a distinct diabetic cardiomyopathy (the Framingham Heart Study). Am J Cardiol 1991, 68:85-89.

7. Zabalgoitia M, Ismaeil MF, Anderson L, Maklady FA: Prevalence of diastolic dysfunction in normotensive, asymptomatic patients with wellcontrolled type 2 diabetes mellitus. Am J Cardiol 2001, 87:320-3.

8. Dinh W, Lankisch M, Nickl W, Scheyer D, Scheffold T, Kramer F, Klein RM, Barroso MC, Füth R: Insulin resistance and glycemic abnormalities are associated with deterioration of left ventricular diastolic function: a cross-sectional study. Cardiovasc Diabetol 2010, 9:63-75.

9. Redfield MM, Jacobsen SJ, Burnett JC, Mahoney DW, Bailey KR, Rodeheffer RJ: Burden of systolic and diastolic ventricular dysfunction in the community: appreciating the scope of the heart failure epidemic. JAMA 2003, 289:194-202.

10. Nicolino A, Longobardi G, Furgi G, Rossi M, Zoccolillo N, Ferrara N, Rengo F: Left ventricular diastolic filling in diabetes mellitus with and without hypertension. Am J Hypertens 1995, 8:382-389.

11. Di Bonito P, Cuomo S, Moio N: Diastolic dysfunction in patients with noninsulin-dependent diabetes mellitus of short duration. Diabetic Med 1996, 13:321-324.

12. Boyer JK, Thanigaraj S, Schechtman KB, Pérez JE: Prevalence of ventricular diastolic dysfunction in asymptomatic, normotensive patients with diabetes mellitus. Am J Cardiol 2004, 93:870-5.

13. Poirier P, Bogaty P, Garneau C, Marois L, Dumesnil JG: Diastolic dysfunction in normotensive men with well-controlled type-2 diabetes: importance of maneuvers in echocardiographic screening for preclinical diabetic cardiomyopathy. Diabetes Care 2001, 24:5-10.

14. Kiencke $S$, Handschin $R$, von Dahlen R, Muser J, Brunner-Larocca HP, Schumann J, Felix B, Berneis K, Rickenbacher P: Pre-clinical diabetic cardiomyopathy: prevalence, screening, and outcome. Eur J Heart Fail 2010, 12:951-7

15. van der Horst IC, de Boer RA, Hillege HL, Boomsma F, Voors AA, van Veldhuisen DJ: Neurohormonal profile of patients with heart failure and diabetes. Neth Heart J 2010, 18:190-6.

16. Albertini JP, Cohen R, Valensi P, Sachs RN, Charniot JC: B-type natriuretic peptide, a marker of asymptomatic left ventricular dysfunction in type 2 diabetic patients. Diabetes Metab 2008, 34:355-62.

17. Rana BS, Davies JI, Band MM, Pringle SD, Morris A, Struthers AD: B-type natriuretic peptide can detect silent myocardial ischaemia in asymptomatic type 2 diabetes. Heart 2006, 92:916-20.

18. Beer S, Golay S, Bardy D, Feihl F, Gaillard RC, Bachmann C, Waeber B, Ruiz J: Increased plasma levels of N-terminal brain natriuretic peptide (NTproBNP) in type 2 diabetic patients with vascular complications. Diabetes Metab 2005, 31:567-73.

19. Magnusson M, Jovinge $S$, Shahgaldi $K$, Israelsson B, Groop L, Melander O: Brain natriuretic peptide is related to diastolic dysfunction whereas urinary albumin excretion rate is related to left ventricular mass in asymptomatic type 2 diabetes patients. Cardiovasc Diabetol 2010, 9:2.

20. Valle R, Bagolin E, Canali C, Giovinazzo P, Barro S, Aspromonte N, Carbonieri E, Milani L: The BNP assay does not identify mild left ventricular diastolic dysfunction in asymptomatic diabetic patients. Eur J Echocardiogr 2006, 7:40-4.

21. Dencker M, Stagmo M, Dorkhan M: Relationship between natriuretic peptides and echocardiography parameters in patients with poorly regulated type 2 diabetes. Vascular Health and Risk Management 2010, 6:373-382 
22. Expert Committee on the Diagnosis and Classification of Diabetes Mellitus: Report of the expert committee on the diagnosis and classification of diabetes mellitus. Diabetes Care 2003, Suppl 1: S5-20.

23. Romano S, Necozione $S$, Guarracini L, Fratini S, Cisternino P, di Orio F, Penco M: Accuracy of $\mathrm{N}$-terminal pro-brain natriuretic peptide in the identification of left ventricular dysfunction in high-risk asymptomatic patients. J Cardiovasc Med (Hagerstown) 2009, 3:238-44

24. Devereux RB, Lutas EM, Casale PN, Kilgfield P, Eisenberger RR, Hammond IW, Miller DH, Reis G, Alderman MH, Laragh JH: Standardization of M-mode echocardiographic left ventricular anatomic measurements. Am Coll Cardiol 1984, 4:1222-1230.

25. De Simone G, Daniels SR, Devereux RB, Meyer RA, Roman MJ, de Divitiis O, Alderman MH: Left ventricular mass body size in normotensive children adults: assessment of allometric relations impact of overweight. J Am Coll Cardiol 1992, 20:1251-1260

26. Menzin J, Langley-Hawthorne C, Friedman M, Boulanger L, Cavanaugh R Potential short-term economic benefits of improved glycemic control: a managed care perspective. Diabetes Care 2001, 24:51-5.

27. Liu JE, Palmieri V, Roman MJ, Bella JN, Fabsitz R, Howard BV, Welty TK, Lee ET, Devereux RB: The impact of diabetes on left ventricular filling pattern in normotensive and hypertensive adults: the Strong Heart Study. J Am Coll Cardiol 2001, 37:1943-9.

28. Betti I, Castelli G, Barchielli A, Beligni C, Boscherini V, De Luca L, Messeri G, Gheorghiade M, Maisel A, Zuppiroli A: The role of N-terminal PRO-brain natriuretic peptide and echocardiography for screening asymptomatic left ventricular dysfunction in a population at high risk for heart failure. The PROBE-HF study. J Card Fail 2009, 15:377-84.

29. Aneja A, Tang WH, Bansilal S, Garcia MJ, Farkouh ME: Diabetic cardiomyopathy: insights into pathogenesis, diagnostic challenges, and therapeutic options. Am J Med 2008, 121:748-757.

30. Andersson C, Gislason GH, Weeke P, Hoffmann S, Hansen PR, TorpPedersen C, Søgaard P: Diabetes is associated with impaired myocardial performance in patients without significant coronary artery disease. Cardiovasc Diabetol 2010, 9:3.

31. Eckel RH, Wassef M, Chait A, et al: Prevention Conference Vl: Diabetes and cardiovascular disease: Writing Group II: Pathogenesis of atherosclerosis in diabetes. Circulation 2002, 105:e138-43.

32. Görmüș U, Ozmen D, Ozmen B, Parildar Z, Ozdoğan O, Mutaf I, Bayindir O: Serum N-terminal-pro-brain natriuretic peptide (NT-pro-BNP) and homocysteine levels in type 2 diabetic patients with asymptomatic left ventricular diastolic dysfunction. Diabetes Res Clin Pract 2010, 87:51-6.

33. Kim JY, Lee EY, Jee JH, Lee BW, Chung JH, Jeun ES, Min YK, Lee MS, Kim KW, Lee MK: N-terminal pro-brain natriuretic peptide (NT-proBNP) in Type 2 diabetes with left ventricular dysfunction. Diabetes Res Clin Pract 2007, 77(Suppl 1):S238-42.

34. Castaño Rodríguez S, Coma-Canella I, López Salazar B, Barba Cosials J: Echocardiographic findings and NT-proBNP level in type-2 diabetic patients with and without ischemic heart disease. Rev Esp Cardiol 2009, 62:1184-8.

35. Gerstein HC, Miller ME, Byington RP, Goff DC, Bigger JT, Buse JB, Cushman WC, Genuth S, Ismail-Beigi F, Grimm RH Jr, et al: Effects of intensive glucose lowering in type 2 diabetes. N Engl J Med 2008, 358:2545-2559.

36. Nathan DM, Cleary PA, Backlund JY, Genuth SM, Lachin JM, Orchard TJ, Raskin $P$, Zinman B: Intensive diabetes treatment and cardiovascular disease in patients with type 1 diabetes. N Engl J Med 2005, 353:2643-2653.

doi:10.1186/1475-2840-9-89

Cite this article as: Romano et al:: Early diagnosis of left ventricular diastolic dysfunction in diabetic patients: a possible role for natriuretic peptides. Cardiovascular Diabetology 2010 9:89.

\section{Submit your next manuscript to BioMed Central and take full advantage of:}

- Convenient online submission

- Thorough peer review

- No space constraints or color figure charges

- Immediate publication on acceptance

- Inclusion in PubMed, CAS, Scopus and Google Scholar

- Research which is freely available for redistribution

Submit your manuscript at www.biomedcentral.com/submit
C Biomed Central 